\title{
Pressure influence on film boiling of mixtures
}

\author{
Arslan Zabirov, Victor Yagov, Pavel Kanin, Vladislav Ryzantcev, Mikhail Vinogradov \\ National Research University, Moscow Power Engineering Institute \\ Moscow, Russia \\ Zabirov.arslan@gmail.com
}

\begin{abstract}
A unique experimental work was carried out to study the laws governing the cooling of subcooled water-ethanol mixtures under pressures up to $0.5 \mathrm{MPa}$. The great intensification of quenching was recorded with increasing pressure and mass fraction of water in ethanol. At some conditions the transition temperature to the intensive boiling regime noticeably exceeded the critical temperature of the liquid (when direct liquid-solid contact is impossible).
\end{abstract}

Keywords: Film boiling, Leidenfrost point, Microbubble boiling, Mixture, Heat transfer.

\section{Introduction}

Unsteady film boiling of subcooled liquids observed in both natural and technological processes. As an example for natural phenomena, one can cite the process of interaction of lava with seawater in the event of an eruption of a coastal or underwater volcano. Examples of technological processes are the quenching of metals and the re-flooding of the core of a nuclear reactor Moreover, the film boiling of subcooled liquids could be an initial process of vapour explosion, and the surface temperature when film boiling lose stability play significant role for this destructive phenomena. Historically, the first studies of non-stationary film boiling were associated with the vapor explosion problem [1, 2]. The result of the experimental research was discovery of a new boiling regime. Based on visual observation, researches named it "microbubble boiling". The main features of this boiling regime are follows:

- Surface temperature higher than critical liquids temperature;

- Subcooling of liquid higher than $22 \mathrm{~K}$.

Experiments were conducted on water and working samples were copper balls with protective nickel coating. The unusual nature of this phenomenon is that it is characterized by huge heat transfer coefficients and, accordingly, cooling rates (up to $1000 \mathrm{~K} / \mathrm{s}$ ), when the temperature of the cooled surface exceeds the liquid homogeneous temperature by hundreds of degrees.

Despite the large number of experimental works, for example [3,4], the physical model explaining the nature and mechanisms of this phenomenon has not been proposed.

Over the past 10 years, our research team has conducted an extensive series of experimental work on various liquids and metals under different conditions [5-10]. The compressed results are shown in Table 1 and 2. There we present results corresponded to stable film boiling (Table 1) and microbubble boiling (Table 2). It includes relation between cooling liquids, metals and experimental conditions (subcooling rate $\Delta T$ sub and pressure $P$ ).

Stable film boiling characterized by low HTC, stable vapor film and observed both in steady or unsteady conditions. We experimentally fixed the stable film boiling by visual observations and by temperature data from thermocouples placed inside the working samples. From Table 1 we can see that stable film boiling present on all metals with different properties, especially heat conduction. It occurs on ethanol, isopropanol and FC-72 (perfluorhexane) in whole temperature range, when it consist in liquid state. Even under high pressures, if the cooling liquid is FC-72, it always stable film boiling. For water the picture is rather different. Stable film boiling regime occurs only on saturate and weakly subcooled water $\left(\Delta T_{\text {sub }}<22 \mathrm{~K}\right)$. 
Table 1: Stable film boiling.

\begin{tabular}{|c|c|c|}
\hline Water & Stainless Steel, Nickel, Copper & $\begin{array}{c}\Delta T_{\text {sub }}<22 \mathrm{~K}, P=0.1-1.0 \\
\mathrm{MPa},\end{array}$ \\
\hline $\begin{array}{l}\text { Ethanol, } \\
\text { Isopropanol }\end{array}$ & Stainless Steel, Nickel, Copper & $\Delta T_{\text {sub }}<170 \mathrm{~K}, P=0.1 \mathrm{MPa}$, \\
\hline FC-72 & Stainless Steel, Nickel, Copper & $\Delta T_{\text {sub }}<120 \mathrm{~K}, P<1.0 \mathrm{MPa}$ \\
\hline
\end{tabular}

Until recently it was believed that microbubble boiling is observed only on water. But our new experiments, conducted in 2017-2018 demonstrate, that this unusual boiling regime occurs on another liquids too, but under specific conditions. As for ethanol, we fixed the appearance of this regime at high pressures (up to 1.0 MPa) on low conductive metal (stainless steel). At such experiments we increased saturation temperature (and, correspondingly $\Delta T_{\text {sub }}$ ), while bulk liquid temperature remain constant. It means that liquid properties was approximately constant. It is very important when we deal with alcohols, because their viscosity increase dramatically when liquid temperature drop. Another interesting results were obtained on water-ethanol mixtures [11].Using liquid mixtures instead of pure components can be considered as a convenient way to investigate influence of the liquid properties. Experiments demonstrated that with ethanol concentration decreasing the process of boiling strengthened and duration of cooling decreased. It means that stable film boiling duration decreased and earlier transition to intensive boiling regime occurred. When water concentration in ethanol becomes higher than $50 \%$ we observe microbubble boiling regime at very high surface temperatures (higher than critical one). Recently we obtained the new experimental results on quenching of stainless steel balls in liquid argon and liquid nitrogen. The experiments were performed on polished, hoarfrost and ice surfaces. The experiments on hoarfrost surface demonstrated high cooling rates in comparison with polished and ices surfaces, even at saturate temperature.

Table 2: Unstable film boiling.

\begin{tabular}{|c|c|c|}
\hline Water & Stainless Steel, Nickel, Copper & $\begin{array}{c}\Delta T_{\text {sub }}>22 \mathrm{~K}, \mathrm{P}=0.1-1.0 \\
\mathrm{MPa}\end{array}$ \\
\hline Ethanol & Stainless Steel & $\Delta T_{\text {sub }}>70 \mathrm{~K}, \mathrm{P}>0.5 \mathrm{MPa}$ \\
\hline $\begin{array}{c}\text { Eth./Water } \\
\text { mix. }\end{array}$ & Stainless Steel & $\omega_{\text {eth }}>50 \%, \mathrm{P}=0.1 \mathrm{MPa}$ \\
\hline $\begin{array}{c}\mathrm{LN}_{2} \text { and } \\
\text { LAr }\end{array}$ & Stainless Steel with hoar frost & Saturated liquid, P $=0.1 \mathrm{MPa}$ \\
\hline
\end{tabular}

The main conclusion of this experimental work is that the microbubble boiling strongly depends on:

- Liquid properties;

- Metal properties;

- Subcooling value;

- Surface condition.

In 2017 scientific group governing by prof.Yagov proposed a model of incipience of highly intensive film boiling regime in subcooled liquid. In detail it presents in [12].The main idea of the model is that the liquid wave can periodically touch surface roughness protrusions; if their temperature appears to be lower than the attainable limiting temperature of a liquid (Tlim), the possibility of direct local contact between liquid and solid wall occurs. In this paper we present results on film boiling of water-ethanol mixture under high pressures. So, according to this model we should observe increasing of temperature of surface when intensive boiling regime starts when we rise a pressure and water concentration in ethanol. 


\section{Experimental facility}

In our experiments we used a unique experimental facility which allows us to conduct experiments at high pressures. The facility body, sealed experimental camera, is made of stainless steel tube $219 \mathrm{~mm}$ outer diameter with a wall thickness thickness of $10 \mathrm{~mm}$. In the stand upper part a coil (2) of a high frequency induction heater (3) is placed; the lower part is is filled with a cooling liquid, the temperature of which is maintained at a predetermined level by means of a thermostat (8) (8) and a coil pipe (7) immersed in the liquid. The heating zone is separated from the liquid by thin metal diaphragm (5), (5), which protects the cooling medium against heat radiation. At the experiment beginning a metal sphere (tested sample) (1) is mounted inside the coil (2) by means of the lever-type displacement system (4). Heating is controlled by 5 type-K thermocouples placed inside the sphere. As a cooling liquid we used water-ethanol mixtures. The concentration of the mixture was set using a float hydrometer with acceptable accuracy.

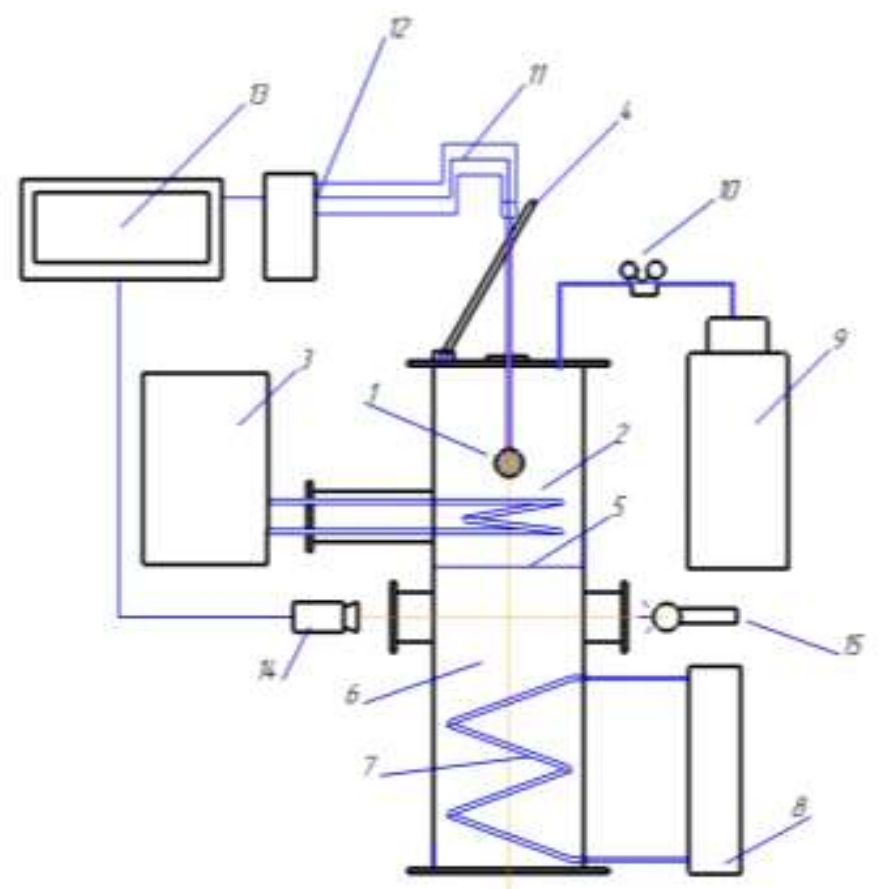

Fig. 1: Experimental facility: (a) schematic of experimental stand: 1 - tested sample, 2 - HF-inductor coil, 3 - HF-inductor, 4 displacement system, 5 - metallic diaphragm, 6 - experimental camera, 7 - coil pipe, 8 - thermostat, 9 - balloon with inert gas, 10 control valve, 11 - thermocouples, 12 - measuring module, 13 - personal computer, 14 - video camera, 15 - halogen lamp; (b) experimental stand photo.

Tested sample is sphere $40 \mathrm{~mm}$ in diameter of stainless steel Aisi-316. 4 thermocouples placed on surface points (inside the ball) with polar angles $45,90,135$ and $180^{\circ}$, and one in the ball centre (Fig. 2).
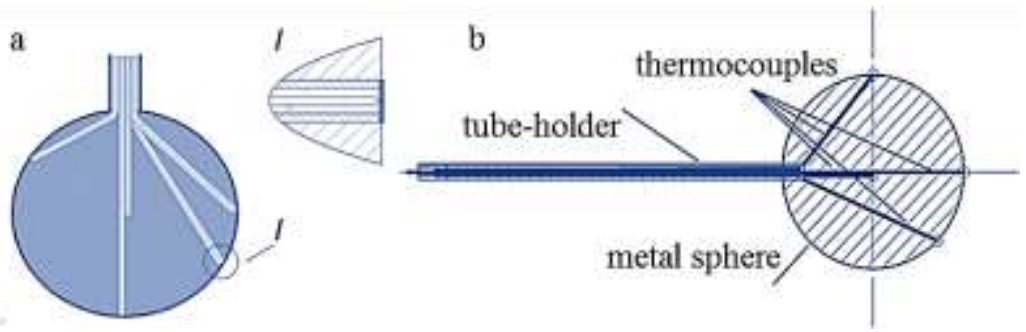

Fig. 2: Schematic of working samples: (a) thermocouple junction connection; (b) general view of the working sample. 
The thermocouple junctions (type K) were welded flush with the surface by means of laser welding, their cables passed through the holes and further to the data acquisition system.

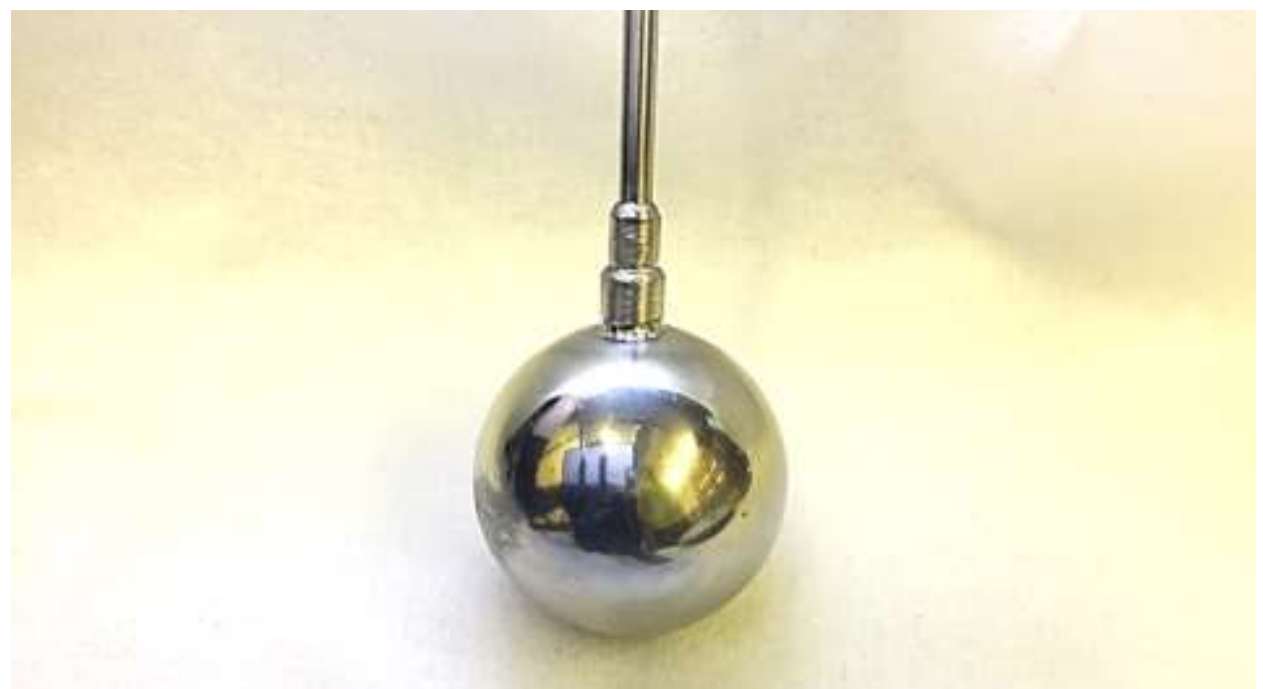

Fig. 3: Photo of stainless steel working sample with polished surface.

\section{Results and discussion}

In current experimental series we used pure ethanol and $80 \%$ ethanol-water mixture. The fixed mixture temperature was $30^{\circ} \mathrm{C}$. First, we performed experiments on pure ethanol under different pressures. Pressure varied from 0.1 to 0.5 $\mathrm{MPa}$.

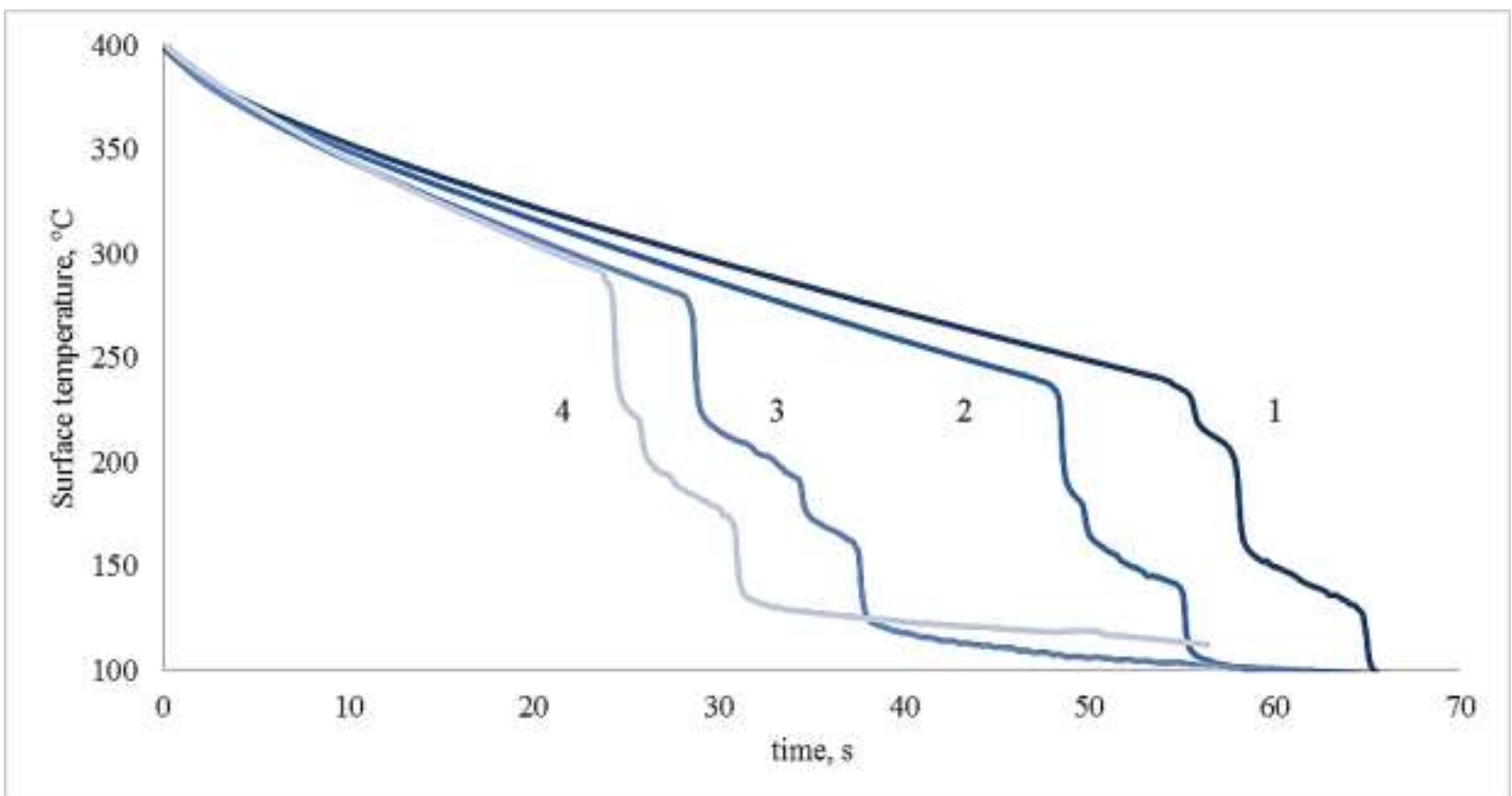

Fig. 4: Averaged surface thermograms of cooling the stainless steel sphere in ethanol at temperature $+30^{\circ} \mathrm{C}$ and pressures: $0.1 \mathrm{MPa}-1$, $0.2 \mathrm{MPa}-2,0.3 \mathrm{MPa}-3$ and $0.5 \mathrm{MPa}-4$. 
As can be seen in Figure 4, the change in pressure has a noticeable effect on the character of quenching. The duration of total cooling process is 65 seconds for ethanol under atmospheric pressure. An increase in pressure to 0.2 MPa does not lead to a noticeable intensification of the process. Stable film boiling becomes more intensive first of all due to decreasing of vapour thickness. However, a further increase in pressure leads to a substantial intensification of process. The total duration of cooling process decreases by 30 seconds. The reason is the increase in the transition temperature when stable film boiling replaced by intensive cooling mode. At 0.1 and $0.2 \mathrm{MPa}$ this temperature is approximately $240^{\circ} \mathrm{C}$. But at 0.3 and $0.5 \mathrm{MPa}$ transition temperature reaches 280 and $290^{\circ} \mathrm{C}$ while the critical temperature of ethanol is $241^{\circ} \mathrm{C}$. It means, that the intensive boiling regime starts when surface temperature exceeds critical liquid temperature which makes direct liquid-solid contact impossible.

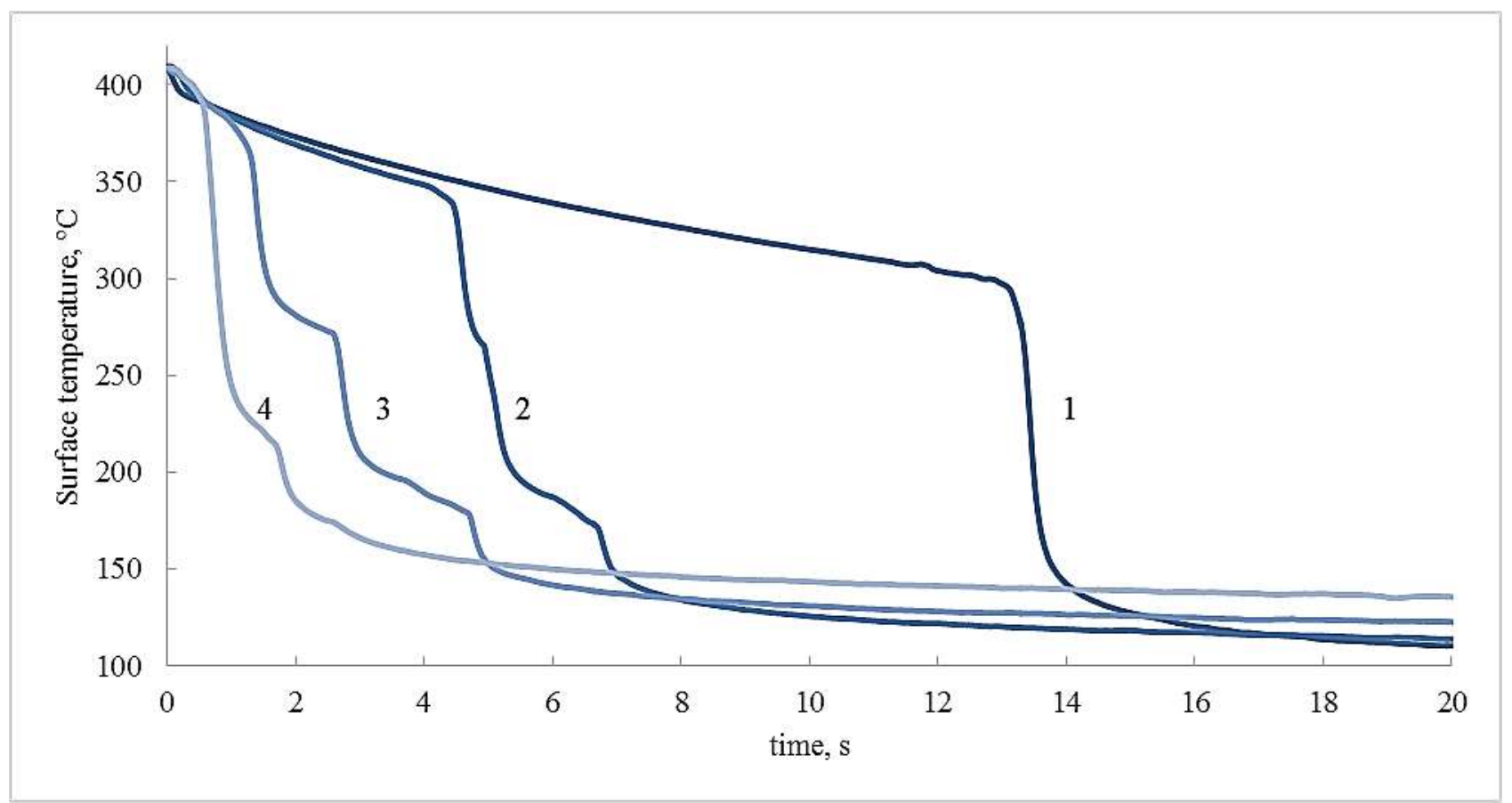

Fig. 5: Averaged surface thermograms of cooling the stainless steel sphere in $80 \%$ water-ethanol mixture at temperature $+30^{\circ} \mathrm{C}$ and pressures: $0.1 \mathrm{MPa}-1,0.2 \mathrm{MPa}-2,0.3 \mathrm{MPa}-3$ and $0.5 \mathrm{MPa}-4$.

When we deal with mixture (20\% of water and $80 \%$ of ethanol), the transient temperature rise becomes more apparent (Figure 5). Now, even at atmospheric pressure the transient temperature is $300^{\circ} \mathrm{C}$. When pressure is $0.2 \mathrm{MPa}$ the transient temperature becomes approximately $350^{\circ} \mathrm{C}$. At 0.3 and $0.5 \mathrm{MPa}$ the transition to high intensive boiling mode occurs right after immersing tested metal ball in mixture that is, at temperatures of about $380-400^{\circ} \mathrm{C}$. These temperatures much higher than critical temperature of water-ethanol $80 \%$ binary mixture which is $278^{\circ} \mathrm{C}$. In comparison with pure ethanol we denote a high intensification of boiling regime, in 5 times at atmospheric pressure and in 15 times at $0.5 \mathrm{MPa}$.

\section{Conclusion}

A unique experimental work was carried out to study the laws governing the cooling of subcooled water-ethanol mixtures under pressures up to 0-5 MPa. The experimental results can draw the following conclusions:

- With increasing pressure, the temperature of the onset of intensive cooling (Leidenfrost temperature) increases.

- With increasing water concentration in ethanol, the temperature of the onset of intensive cooling increases.

The question that requires further discussion is that the transition temperature to the intensive boiling regime noticeably exceeded the critical temperature of the liquid (when direct liquid-solid contact is impossible). 


\section{Acknowledgements}

This study was conducted in National Research University "Moscow Power Engineering Institute" at the expense of the Russian Science Foundation, Grant No. 17-79-20402.

\section{References}

[1] S. Aziz, G. F. Hewitt, D. B. R. Kenning, "Heat transfer regimes in forced-convection film boiling on spheres," in Proc. 8th Int. Heat Transfer Conf., vol. 5, pp. 2149-2154, 1986.

[2] Y. Zvirin, G. R Hewitt, and D. B. R. Kenning, "Boiling on free-falling spheres: drag and heat transfer coefficients," Experimental Heat Transfer, vol. 3, no. 3, pp. 185-214, 1990.

[3] H. Yeom, H. Jo, G. Johnson, K. Sridharan, M. Corradini, "Transient pool boiling heat transfer of oxidized and roughened Zircaloy-4 surfaces during water quenching," International Journal of Heat and Mass Transfer, vol. 120, pp. 435-446, 2018.

[4] V. G. Zhilin, Yu. A. Zeigarnik, Yu. P. Ivochkin, A. A. Oksman, and K. I. Belov, "An experimental investigation into the characteristics of subcooled water flashing on a hot surface during a change of boiling modes," Teplofiz. Vys. Temp. vol. 47, no. 6, pp. 891-898, 2009.

[5] V. V. Yagov, A. R. Zabirov, M. A. Lexin, "Unsteady heat transfer during subcooled film boiling," Thermal Engineering, vol. 62, pp. 833-842, 2015.

[6] V. V. Yagov, M. A. Lexin, A. R. Zabirov, O. N. Kaban'kov, "Film boiling of subcooled liquids. Part I: Leidenfrost phenomenon and experimental results for subcooled water," International Journal of Heat and Mass Transfer, vol. 100 pp. 908-917, 2016.

[7] V. V. Yagov, M. A. Lexin, A. R. Zabirov, M. A. Denisov, "Film boiling of subcooled liquids. Part II: Steady regimes of subcooled liquids film boiling," International Journal of Heat and Mass Transfer, vol. 100, pp. 918-926, 2016.

[8] A. R. Zabirov, V. V. Yagov, O. N. Kaban'kov, M. A. Lexin, P. K. Kanin, "Pressure influence on steady film boiling of subcooled liquids," Journal of Engineering Physics and Thermophysics, vol. 89, pp. 1466-1475, 2016.

[9] V. V. Yagov, A. R. Zabirov, R. K. Kanin, M. A. Denisov, "Heat Transfer in Film Boiling of Subcooled Liquids: New Experimental Results and Computational Equations," Journal of Engineering Physics and Thermophysics, vol. 90, pp. 266-275, 2017.

[10] V. V. Yagov, A. R. Zabirov, O. N. Kaban'kov, M. V. Minko, "Heat transfer during cooling of high temperature spheres in subcooled water at different pressures," International Journal of Heat and Mass Transfer, vol. 110, pp. 219-230, 2017.

[11] A. R. Zabirov, V. V. Yagov, P. K. Kanin, "Intensive cooling metallic bodies with low thermal conductivity in film boiling of ethanol," Journal of Physics: Conference Series, vol. 891, 2017.

[12] V. V. Yagov, A. R. Zabirov, P. K. Kanin, "Heat transfer at cooling high-temperature bodies in subcooled liquids," International Journal of Heat and Mass Transfer, vol. 126, pt. A, pp. 823-830, 2018. 